\title{
LOS ORÍGENES CONTEMPORÁNEOS DEL CENTRALISMO FISCAL EN LAS RELACIONES INTERGUBERNAMENTALES EN MÉXICO $(1970-1990)^{*}$
}

\author{
JOSÉ GERARDO MORENO AYALA** \\ UNIVERSIDAD AUTÓNOMA DEL ESTADO DE MÉXICO
}

Recibido/ Received/ Recebido: 11/06/14 - Aceptado/ Accepted / Aprovado: 04/09/14

\begin{abstract}
Resumen
El presente trabajo analiza la consolidación del centralismo fiscal en México a partir de las reformas fiscales que se instrumentaron entre 1970 y 1990, en contradicción con la estructura federal de la República Mexicana. El centralismo fiscal surgido de este proceso de reformas institucionales determinó dos rasgos fundamentales de las relaciones fiscales intergubernamentales contemporáneas en México, por un lado, la centralización del poder de decisión sobre el sistema fiscal en el Gobierno federal y, por el otro, la conformación de unos gobiernos locales dependientes de la política fiscal y las transferencias de recursos federales. Ambos han sido factores cruciales en la debilidad fiscal del Estado mexicano.

Palabras clave: Federalismo fiscal; Centralismo fiscal; Historia fiscal; Autonomía fiscal; Finanzas públicas; México.
\end{abstract}

\section{THE ORIGINS OF CONTEMPORARY FISCAL CENTRALISM IN INTER- GOVERNMENTAL RELATIONS IN MEXICO (1970-1990)}

\begin{abstract}
This paper analyzes the consolidation of fiscal centralism in Mexico from tax reforms that were implemented between 1970 and 1990, contrary to the federal structure of the Mexican Republic. Fiscal centralism emerged from this process of institutional reforms identified two fundamental features of contemporary intergovernmental fiscal relations in Mexico, on the one hand, centralization of decision-making on the tax system in the federal government and, on the other, the creation of a dependent local governments on fiscal policy and transfers of federal resources. Both have been crucial factors in the fiscal weakness of the Mexican State.

Keywords: Fiscal federalism; Fiscal centralism; Tax history; Fiscal autonomy; Public finances; Mexico.
\end{abstract}

Producto de investigación derivado del proyecto: "Hacia una propuesta institucional - evolucionista para el federalismo fiscal mexicano, en materia de ingresos gubernamentales". Investigación realizada en 2012, sin financiamiento.

* Maestro en Ciencias Sociales con Especialidad en Desarrollo Municipal por El Colegio Mexiquense, A. C., profesor-investigador en la Facultad de Planeación Urbana y Regional de la Universidad Autónoma del Estado de México. Correo electrónico:jgma56@gmail.com. 


\title{
AS ORIGENS CONTEMPORÂNEAS DO CENTRALISMO FISCAL NAS RELAÇÕES INTERGOVERNAMENTAIS NO MÉXICO (1970-1990)
}

\begin{abstract}
Resumo
O presente trabalho analisa a consolidação do centralismo fiscal no México a partir das reformas fiscais que se instrumentaram entre 1970 e 1990, em contradição com a estrutura federal da República Mexicana. O centralismo fiscal surgido deste processo de reformas institucionais determinou dois traços fundamentais das relações fiscais intergovernamentais contemporâneas no México: por um lado, a centralização do poder de decisão sobre o sistema fiscal no Governo Federal e, por outro, a formação de uns governos locais dependentes da política fiscal e das transferências de recursos federais. Ambos têm sido fatores cruciais na debilidade fiscal do Estado mexicano.

Palavras chave: Federalismo fiscal; Centralismo fiscal; História fiscal; Autonomia fiscal; Finanças públicas; México.
\end{abstract}

Moreno, J. (2015) Los orígenes contemporáneos del centralismo fiscal en las relaciones intergubernamentales en México (1970-1990). En: Revista de la Facultad de Ciencias Económicas de la Universidad Militar Nueva Granada. rev.fac.cienc.econ, XXIII (2), DOI: http://dx.doi.org/10.18359/rfce.1615.

JEL: H20, H30, N46.

\section{Introducción}

Estudiar las finanzas públicas de un país en las últimas décadas del siglo XX es de la mayor relevancia porque luego del largo periodo de crecimiento y estabilidad de la posguerra, la economía mundial entró en una etapa de crisis y profundos desajustes, entre los cuales estuvo la crisis fiscal del Estado, agravada por el proceso de endeudamiento externo. Aun cuando siempre fue un tema polémico, la situación económica de aquélla época impulsó nuevamente la discusión en torno al papel del Estado en la economía. Si bien no es objeto del presente trabajo considerar las vicisitudes de la discusión teórica y política en el diseño del Estado y sus formas de intervención, es pertinente señalar que su resultado llevó a la instrumentación del programa económico y político neoliberal a escala mundial; por supuesto que ahora sabemos que es, temporalmente, una corriente vencedora, pero sin éxito.

En el periodo que se analiza, nuestro país pasó de ser una nación con un peso importante del Estado en la economía, en el contexto de una economía cerrada, a iniciar un proceso de aplicación de las reformas de mercado que posteriormente se definirían como la instrumentación del Consenso de Washington. Las crisis fiscales que han enfrentado los gobiernos locales en México en las últimas décadas, además de las permanentes dificultades para impulsar el desarrollo de sus jurisdicciones (Massolo, 1989 y Tamayo y Hernández, 2006), determinó la necesidad de considerar el periodo histórico en el cual se consolidó el centralismo fiscal. Ese periodo cubre las décadas de 1970 a 1990, en el cual el Gobierno federal incrementó su papel dominante en las relaciones fiscales intergubernamentales.

El análisis de este tema de las finanzas públicas busca satisfacer la inquietud que despierta conocer la historia reciente de la configuración del sistema de relaciones fiscales intergubernamentales en México, que a pesar de los discursos, planes y programas gubernamentales y de la alternancia política no ha reducido su perfil centralista y de gobiernos locales dependientes de las transferencias de recursos financieros del Gobierno federal. Entonces, la finalidad del presente trabajo es analizar la dinámica y características del proceso de centralización fiscal contemporáneo en las relaciones fiscales intergubernamentales en México entre 1970 y 1990, que constituye el periodo histórico en el cual se sientan las bases del moderno centralismo fiscal mexicano y que, como se muestra en la Gráfica 1 , 
tiene desde entonces como uno de sus corolarios la dependencia financiera de los gobiernos de las entidades federativas y municipios; o lo que es lo mismo, el escaso peso que tienen los ingresos propios de los gobiernos locales en el total de sus ingresos. Así, en 2008, considerando el total de las transferencias federales, que comprende tanto las no condicionadas o Participaciones federales como las de carácter condicionado o Aportaciones federales, los ingresos autónomos ${ }^{1}$ de estados, Distrito federal y municipios, apenas representaron, en el mismo orden, 14, 36 y 26 por ciento de sus ingresos totales.

Gráfica 1. México: Dependencia y autonomía fiscal de los gobiernos locales, 2008 (Porcentajes)

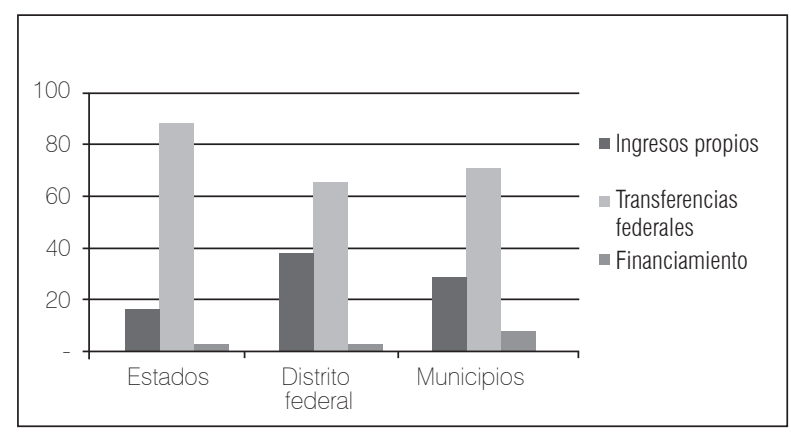

Fuente: Elaboración propia con base en INEGI (2010).

Para señalar la importancia de los ingresos gubernamentales bastaría con indicar que su función más importante es financiar el gasto público ${ }^{2}$. Sin embargo,

1 La autonomía financiera se midió como la relación entre los ingresos propios (impuestos, derechos, productos, aprovechamientos y contribución de mejoras) respecto a los ingresos totales, excluyendo los ingresos por cuenta de terceros, pero incluyendo el financiamiento y las transferencias federales tanto condicionadas como no condicionadas.

2 Debe considerarse que el gasto público depende de la formación económica y social de cada país en un momento histórico determinado. También es importante destacar la influencia que ejerce la teoría y política en la política fiscal, como puede ser la teoría del Estado Benefactor que impulsó la intervención del Estado en la economía en la segunda posguerra mundial o el Consenso de Washington en el más reciente cambio de siglos y que propone la reducción del papel del Estado en la economía. Por supuesto que las consecuencias del tamaño y papel del Estado en la economía son cruciales para el desarrollo económico y el bienestar de la población. En la medida que los ingresos estén en función del gasto se puede calcular, indirectamente, la importancia del gasto público a través de la carga fiscal (= [ingresos públicos/producto interno bruto] x 100). Así, datos a los ingresos públicos se les han asignado no menos importantes tareas económicas y sociales, aún cuando éstas pueden depender, en un sistema federal, del nivel de gobierno al cual se esté haciendo referencia. Al efecto y para el caso del gobierno central, la teoría de las finanzas públicas señala su papel en la redistribución de la renta nacional o la de ser, como parte de la política macroeconómica, un instrumento para favorecer un crecimiento económico estable y equilibrado; esto, al gravar las actividades económicas de manera diferenciada o incluso proteger las nacionales de la competencia internacional mediante aranceles ${ }^{3}$. Para el caso de los gobiernos locales este enfoque económico considera que estos tendrían,

para 1975 indican que la carga fiscal en Suecia, Reino Unido, Canadá, Estados Unidos, Nueva Zelanda, Japón y España alcanzó 43.9, 35.5, 33.0, 29.6, 29.6, 20.9 y 19.6 por ciento, respectivamente. Para 1987, la carga fiscal había aumentado notablemente pues pasó, en el mismo orden, a 56.7, 37.5, 34.5, 30.0, 38.6, 30.2 y 33 por ciento (Case y Fair, 1993: 73). En México, la carga fiscal de acuerdo con estimaciones propias pasó, para los mismo años, de 12.69 a 16.72 por ciento. Las cifras de la carga fiscal que se presentan, incluyen los ingresos de los gobiernos centrales y locales.

3 Para los economistas neoclásicos, en particular para los exponentes de las expectativas racionales, "Las funciones que estarían encomendadas al Estado serían la defensa de la nación frente a sus enemigos exteriores y la protección de los ciudadanos frente a los abusos de sus propios conciudadanos. Escrito en términos menos románticos, el Estado debe ser un 'guardián' o policía, que vigile que operen 'libremente' las leyes del mercado" (Villareal, 1986, p. 99). Los neoliberales sociales consideran que la participación del Estado debe aumentar, sólo en la medida que las condiciones de extrema miseria de la población hagan necesaria una política de redistribución del ingreso. Pero el principio ético que debe regir la redistribución de la renta en una sociedad de mercado libre es la de "a cada uno, según lo que él y los instrumentos que él posee producen" (Villareal, 1986, p. 462). Por ello, los impuestos progresivos sobre la renta son virulentamente tachados de confiscatorios y ni siquiera las ayudas para educación o salud se justifican, pues impiden el uso eficiente de los recursos. "En Estados Unidos se han diseñado programas de ayuda social, seguro de desempleo y muchos otros más para ayudar a los pobres. No obstante, en años recientes, el gobierno ha reducido en forma considerable su participación en la redistribución del ingreso. Los recortes de presupuesto y las reducciones fiscales del gobierno de Reagan colocaron de nuevo a Estados Unidos en la senda de distribución del ingreso determinada por el mercado, en lugar de la determinada por políticas gubernamentales. Hay quienes afirman que gravar [con] impuestos a los ricos y establecer programas para los pobres sólo sirve para destruir los incentivos que le ofrece el mercado al trabajo arduo, la iniciativa y los riesgos" (Case \& Fair, 1993, p 55-56). 
fundamentalmente, la tarea de proveer bienes públicos locales de acuerdo con las distintas preferencias y jurisdicciones de los consumidores.

Por otra parte, de acuerdo con este enfoque, también debe tenerse en cuenta que, en el caso de los gobiernos locales, estos se asientan en regiones con diferente nivel de desarrollo. Derivado de tales desequilibrios, muchos de los gobiernos locales pueden no tener las posibilidades de recaudar los ingresos suficientes que les permitan alcanzar un desarrollo sostenido y equilibrado o, por lo menos, satisfacer las necesidades de bienestar de su población por lo que se hace necesario que reciban transferencias de otro ámbito de gobierno (Stiglitz, 1988: 750-753).

Salvo excepciones, después de la Segunda Guerra Mundial, en América Latina se ha dado un proceso de centralización de los recursos públicos, favorable al ámbito de gobierno central. Esta centralización fiscal ha respondido, sin duda, a las necesidades que impuso el proceso de acumulación de capital en la fase de la industrialización y urbanización que se registró en el continente en el siglo XX. Contrariamente a lo ocurrido en nuestras latitudes, en los países más desarrollados los gobiernos centrales han estado transfiriendo capacidades de tributación soberanas a los gobiernos locales (Moreno, 2007a, 2007b). Destaca el hecho de que México es una de las naciones en donde los gobiernos locales son los que relativamente tienen una capacidad de recaudación de ingresos propios menor.

\section{Prolegómenos teóricos de las relacio- nes fiscales intergubernamentales}

El estudio de las relaciones fiscales intergubernamentales en un sistema federal se ha realizado principalmente desde el enfoque de la economía del bienestar, nutrida de las aportaciones seminales de Arrow, Musgrave y Samuelson ${ }^{4}$. Este cuerpo teóri-

$4 \quad$ La naturaleza de los bienes públicos constituye el aporte de Samuelson, mientras que Arrow argumenta sobre el papel económico de los sectores público y privado y, finalmente, Musgrave desarrolla el papel activo y favorable que puede desempeñar el gobierno en la corrección de las distintas fallas del mercado, así como lograr la estabilización macroeconómica a través de políticas fiscales y monetarias y, por supuesto, en promover una equitativa distribución del ingreso (Oates, 2005). co tiene su fundamento en la teoría del consumidor. Para ésta, el gobierno está encargado de proveer a la sociedad de los bienes en los cuales el mercado tiene fallas, como sería el caso de los bienes públicos ${ }^{5}$, las externalidades, los fallos de competencia e información, así como la existencia de mercados incompletos, circunstancias todas ellas que no permiten una asignación eficiente de los recursos económicos a través de los mercados privados y, por lo tanto, la maximización del bienestar. Sin embargo, cuando la demanda de estos bienes ofertados por instituciones públicas no es homogénea especialmente, en caso de que un gobierno central fuera el encargado de satisfacerla, tendería a ofrecer los mismos bienes en todas las regiones, independientemente de las distintas preferencias existentes en ellas, incurriendo con ello en una ineficiente asignación de los recursos. Entonces, para el caso de los bienes públicos locales, se considera que los gobiernos locales son quienes mejor pueden responder a las demandas diferenciadas de los consumidores de bienes públicos y, por lo tanto, la mayoría de las investigaciones concluyen que debe darse una transferencia de recursos a los gobiernos locales en función de la provisión de bienes públicos locales, ya sea bajo la forma de mayores soberanías fiscales o a través de un aumento en las ayudas federales. Interesa entonces a esta vertiente teórica conocer la demanda de bienes públicos nacionales y locales a escala regional y, por lo tanto, busca saber sobre las necesidades de cada nivel de gobierno en cuanto a gasto público se refiere y, entonces, calcular la cantidad de recursos necesarios para cada jurisdicción territorial.

Complementarios al tema de distribución de competencias, están los argumentos de que la eficiencia en la recaudación de cada impuesto se logra a diferentes escalas, lo cual requiere que las distintas instancias gubernamentales administren uno u otro

\footnotetext{
"...hay ciertos bienes -denominados bienes públicos- que la economía privada de mercado no puede proveer. Su característica básica reside en que, si están disponibles, tienen que estarlo por igual para todos los individuos. No puede excluirse a nadie de sus beneficios. Por eso no pueden producirse ni venderse sobre una base lucrativa. La defensa nacional es el ejemplo más claro" (Due \& Friedlaender, 1981: 3). En el caso que la provisión de los bienes públicos sea realizada a través del mercado, ésta será insuficiente y se generará una pérdida de bienestar.
} 
gravamen. Así, por ejemplo, con el fin de globalizar con fines recaudatorios el ingreso de los causantes se considera eficiente que el impuesto sobre la renta lo administre el Gobierno federal, en tanto que ciertos impuestos indirectos como el que se aplica al valor agregado lo pueden hacer los estados. Por otro lado, debido a la inmovilidad de la propiedad territorial, se considera conveniente que los impuestos predial o al traslado de dominio de la propiedad inmobiliaria lo lleven a cabo los municipios.

Entonces, en la mayoría de los trabajos sobre el federalismo fiscal, desde el enfoque de la economía del bienestar, se estudia qué funciones ejerce cada uno de los gobiernos del sistema federal y su eficiencia en la recaudación fiscal, para entonces definir qué proporción de los recursos públicos nacionales es conveniente que queden bajo su jurisdicción.

En México existe una preocupación por las consecuencias de trasladar fuentes impositivas a las entidades federativas y sus municipios por las enormes diferencias regionales, debido a que unas pocas entidades federativas concentran las fuentes de recaudación fiscal ${ }^{6}$. La consecuencia de este tipo de políticas de descentralización sustentadas en el traslado de soberanías fiscales, se argumenta, podría agravar los desequilibrios regionales ${ }^{7}$. También se ha dado importancia al argumento de que en la medida que la hacienda federal es más eficiente, debe ser ella la que recaude la mayoría de los ingresos gubernamentales, y que sea a través de transferencias fiscales a los estados y municipios como se redistribuyan los ingresos fiscales (Tamayo \& Hernández, 2006, p. 4445). En consecuencia, proponen a las transferencias

$6 \quad$ "(...) no es necesaria la presentación de muchos indicadores económicos para demostrar la desigual estructura y el diferente grado de desarrollo económico regional, ni para observar que estas características económicas son un factor delimitante de la política fiscal de los gobiernos locales" (Flores, citado por Anguiano Equihua, s.f., p. 358).

7 “(...) a principios del régimen del presidente Miguel de la Madrid (...) se sugirió (...) que el [Impuesto sobre la Renta] ISR pasara a ser un impuesto estatal...Con este cambio sólo se beneficiarían 12 entidades que concentraban $90 \%$ de la recaudación y recibían sólo $60 \%$ de las participaciones". [Por otra parte, el traslado del Impuesto al Valor Agregado] "(...) sólo beneficiaría a tres entidades (el Distrito Federal; Nuevo León y el estado de México), en las que la recaudación del IVA superaba a las participaciones" (Jannetti, 1989, p. 772). intergubernamentales como el mecanismo idóneo para lograr una distribución más equitativa de los recursos públicos entre los tres ámbitos de gobierno.

Para este enfoque teórico, el problema se reduce prácticamente a una cuestión técnica, en la que los sujetos sociales no son más que consumidores de bienes públicos sin ningún atributo político e histórico $^{8}$. Sin embargo, debido tanto a factores teóricos como históricos (en estos últimos se encuentran las dinámicas descentralizadoras dentro de los Estadosnación o la conformación de uniones o bloques de Estados o las estructuras supranacionales derivadas de los procesos de globalización contemporáneos), se ha ido conformando un cuerpo teórico del federalismo fiscal renovado, sin que haya perdido su "cercanía" con el enfoque tradicional de la economía del bienestar, y que para Oates (2005), siguiendo a otros autores como Qian y Weingast, lleva a la conformación de la Teoría de Segunda Generación del Federalismo Fiscal. Las vertientes en las que abrevia esta nueva versión del federalismo fiscal son los problemas del agente y el principal, la economía de la información, la nueva teoría de la empresa, la teoría de la organización y la teoría de los contratos. En suma, las dos principales fuentes teóricas que estructuran esta Segunda Generación del Federalismo Fiscal son, por un lado, la teoría de la elección pública y la nueva economía política que analiza los agentes y procesos políticos y, por otro, los problemas de fallos en la información en la toma de decisiones de los agentes económicos.

Por supuesto que esta versión renovada de la teoría del federalismo sigue aherrojada en el individualismo metodológico de unos agentes que si bien se desenvuelven en un contexto más amplio de relacio-

\footnotetext{
"La teoría del federalismo fiscal de primera generación asumió la estructura federal como dada, estable y con la capacidad de perpetuarse a sí misma. Dentro de esta estructura dada, la literatura económica sobre el federalismo fiscal examinó la asignación de funciones entre niveles de gobierno y las propiedades de las diferentes instituciones fiscales intergubernamentales. Pero, como muchos de los trabajos recientes (y algunos anteriores) han puesto en relieve, este es un supuesto que no puede considerarse a la ligera. La estabilidad y permanencia de las instituciones federales y, ciertamente el propio Estado-nación, no son inviolables" (Traducción libre de Oates, 2005, p. 366).
} 
nes económicas y políticas y con una "liberación" de ciertos supuestos demasiado estrechos, como el de la racionalidad, que ahora se reconoce limitada, siguen fundándose en el mercado como categoría ahistórica y escenario que rige el conjunto de las relaciones económicas, políticas, sociales e institucionales.

La teoría ortodoxa del federalismo es, sin duda, la corriente predominante y requiere un esfuerzo romper con el efecto paradigma que genera en el análisis de las relaciones fiscales intergubernamentales. El propósito del presente análisis es abordar únicamente uno de los aspectos de esas relaciones fiscales, el de la consolidación del centralismo fiscal y no el de formular formalmente una teoría alternativa al federalismo fiscal. Sin embargo, la importancia de emprender el análisis de los rasgos que presentó la consolidación del centralismo fiscal es crucial pues permite tomar distancia, con evidencia empírica pertinente, respecto de los discursos políticos dominantes que postulaban un proceso de descentralización fiscal y en otras dimensiones de la vida nacional, que fortalecía a los gobiernos locales y con ellos a la vida democrática de México. Pese a ello, no implica que no existan sustentos teóricos y marcos interpretativos diferentes a la teoría tradicional del federalismo fiscal, desde los cuales se puedan interpretar las relaciones fiscales intergubernamentales en su devenir histórico y en el marco más amplio de las transformaciones tecnológicas, económicas, sociales, políticas contemporáneas.

En este trabajo se considera que las relaciones fiscales intergubernamentales están inscritas en procesos histórico-espaciales y no en formas abstractas, por lo cual, retomando los postulados del evolucionismo económico y el viejo institucionalismo ${ }^{9}$, se considera que son las fuerzas tecnoeconómicas y socioinstitucionales las que en el largo plazo constituyen los determinantes objetivos y subjetivos que es necesario incorporar al análisis de las relaciones fiscales intergubernamentales.

Para abundar en lo anterior, remitimos a los lectores interesados en la literatura a los acercamientos teóri-

$9 \quad$ Para una exposición de las diferencias entre el viejo y nuevo institucionalismo ver a Hodgson (2001). cos e interpretativos que se han formulado respecto a las relaciones fiscales intergubernamentales en México, desde una perspectiva institucional y evolucionista. En primer lugar en Moreno (2005) se exponen las líneas teóricas y metodológicas básicas de los enfoques keynesianos, postkeynesianos, economía evolucionista y las características esenciales del proceso de globalización, en especial las políticas de desmantelamiento del Estado de Bienestar e incluyendo, dentro de ellas, las políticas de descentralización de las funciones públicas y la necesidad de abundar en la discusión de marcos interpretativos adecuados a las transformaciones tecnoeconómicas y socioinstitucionales que se gestaron en las dos últimas décadas del Siglo XX. Posteriormente, en Moreno (2007a) se abordan las relaciones entre el federalismo fiscal y la revolución tecnoeconómica y socioinstitucional que se estaba configurando en la transición de siglos; se analizan las consecuencias para las estructuras federales del despliegue nacional y centralista del Estado-nación durante el paradigma fordista-keynesiano para posteriormente analizar las consecuencias del capitalismo informático-global como nuevo paradigma tecnoeconómico en las estructura y funciones del Estado-nación y del sistema de naciones a través de la relativización de la escala que genera la compresión espacio-temporal de la revolución tecnológica. En Moreno (2007b) se exponen las principales tesis de las escuelas del institucionalismo económico y del evolucionismo económico que se consideraron pertinentes para abordar el análisis de los sistemas fiscales y, más particularmente, los ingresos intergubernamentales; a partir de esa plataforma se analiza la estructura de los ingresos de los gobiernos federal, estatales y municipales para los años 1980 y 2002.

\section{Las reformas fiscales interguberna- mentales de fines del siglo $X X$ en México $i$ El principio del fin del cen- tralismo?}

México se caracteriza constitucionalmente como un país federal. Sin embargo, desde la Constitución de 1857 la delimitación de las bases fiscales de esa forma de gobierno fue débil. Con la Constitución de 1917 tampoco se resolvió cabalmente el problema, pues si bien se definieron algunos rubros impositivos como propios del 
Gobierno federal, muchos otros no fueron asignados en exclusividad a algún ámbito de gobierno, por lo que se generó el problema de la múltiple tributación.

Ante esta indefinición constitucional e inadecuada estructura recaudatoria, desde las primeras décadas del siglo XX se realizaron Convenciones Nacionales Fiscales que trataron de concertar entre los gobiernos estatales, municipales y federal los problemas de concurrencia fiscal, así como los apoyos a las entidades más necesitadas de recursos públicos. Concomitantemente con este proceso se dio una centralización de los recursos públicos en las arcas del Gobierno federal, mientras que los gobiernos locales vieron disminuidas sus atribuciones soberanas en materia de recaudación de ingresos (Gráfica 2).

Gráfica 2. México: Ingresos del federalismo, 1930 - 1960 (Porcentajes)

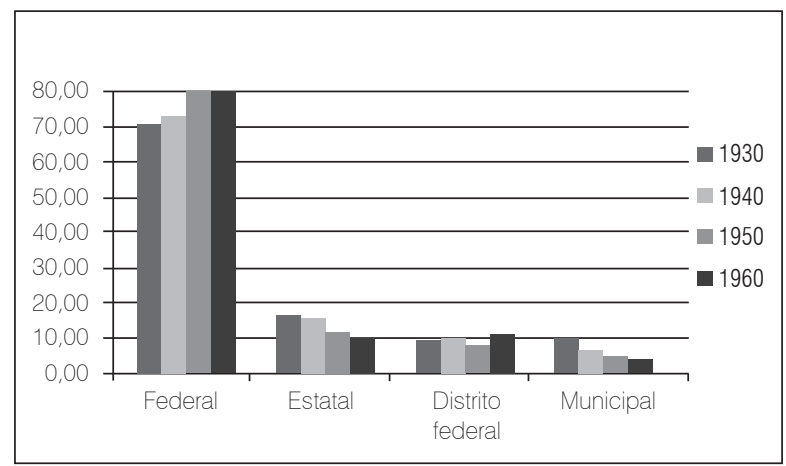

Fuente: Elaborado con base en González (1989, 243-244).

El proceso de centralización fiscal se desarrolló mediante dos vías: la constitucional y la fundada en convenios de coordinación fiscal entre Gobierno federal y las entidades federativas. La constitucional, salvo el caso de la reforma de 1983, se desenvolvió durante la primera mitad del siglo pasado. La vía basada en convenios de coordinación fiscal ha avanzado mediante acuerdos entre los gobiernos de la República, de tal manera que los gobiernos estatales cedieron, abrogaron o suspendieron fuentes impositivas propias o de los ayuntamientos, con el fin de que el Gobierno federal se apropiara de ellas. En contrapartida, el Gobierno federal les otorgó transferencias no condicionadas o participaciones federales a los gobiernos locales.
En un primer momento el proceso de centralización fiscal tuvo como particularidad que la soberanía sobre las fuentes impositivas se concentraba en el Gobierno federal fundamentalmente a partir de reformas constitucionales que establecían áreas exclusivas de gestión o tributación a este ámbito de gobierno; en algunos casos se otorgaba participación en los ingresos ya federales a las haciendas locales. A partir de que el proceso de centralización avanzó mediante mecanismos de coordinación, las participaciones federales van adquiriendo una importancia cada vez mayor en las relaciones fiscales intergubernamentales. Por esta circunstancia es importante hacer una distinción de los montos de los ingresos públicos en antes y después de la distribución de las participaciones federales (Gráficas 3 y 4 ).

Es importante considerar que en las dos décadas del siglo XX que comprende el análisis, México siguió una dinámica económica y social particularmente singular. En los años setenta el producto interno bruto registró un crecimiento promedio anual de 6.7 por ciento, aún cuando a mediados de la década, antes de iniciar el boom petrolero y de deuda externa, se presentó un enlentecimiento en el crecimiento. Por el contrario, los años ochenta constituyó en materia de crecimiento una década perdida, pues el crecimiento promedio anual apenas alcanzó 1.7 por ciento. En ese lapso el país registró una crisis agrícola que aún no tiene visos de superarse y que, muy por el contrario, podría agravarse o, por lo menos, hacerse aún más contradictoria, debido a sus elementos de economía campesina y de subsistencia, por una parte $y$, por otra, a una agricultura empresarial. También en ese lapso nos hemos hecho una nación más desigual, pues de 1976 a principios de los años noventa los salarios perdieron más de la mitad del poder adquisitivo que tenían en aquel año, en tanto que el excedente de explotación, como porcentaje del ingreso nacional pasó de $54.9 \%$ en 1976 a 63.6\% en 1986 (Nacional Financiera, 1988, p. 62, 73). De igual manera, también fuimos un país que haciendo abstracción de la caída global en nuestros términos de intercambio en las transacciones comerciales internacionales, gracias a la renta internacional por nuestros recursos 
naturales ${ }^{10}$ obtuvimos ingresos extraordinarios del exterior por nuestras exportaciones petroleras.

Elemento determinante de la economía mexicana fue el creciente peso del endeudamiento externo, que derivó en cada vez mayores montos de servicio de la deuda externa. De acuerdo con López (2012), el servicio de la deuda externa pasó de niveles de 3 mil millones de dólares anuales en la década de los setenta, a montos superiores a los 10 mil millones durante la década pérdida e incluso en algunos años ascendieron hasta los 20 mil millones de dólares.

Como aspectos importantes a destacar en las finanzas públicas de México en los años setenta y ochenta, tenemos que el déficit financiero del sector público pasó de $7.5 \%$ del producto interno bruto (PIB) en 1980 a 16\% en 1987 (cálculos con base en Nacional Financiera, 1988); el pago de intereses por parte del sector público creció desorbitadamente, ya que mientras en 1977 éste representó 9.3\% del gasto público, en 1987 significó $43.9 \%$, por lo cual el gasto en obra pública se redujo entre 1977 y 1988 de 7.9 como porcentaje del gasto presupuestal a uno por ciento.

En estos años también se dan sustanciales modificaciones en la coordinación fiscal entre los gobiernos estatales y municipales con el Gobierno federal. En esta coordinación es importante destacar que hay un traslado de ingresos de soberanía estatal a los gobiernos Federal y municipal. El primero se beneficia con los cambios en las tasas impositivas del Impuesto sobre Ingresos Mercantiles (ISIM) ${ }^{11}$ y su posterior dero-

10 "Si los productos petroleros se venden domésticamente, entonces la renta implica para los sectores no rentistas una menor tasa de ganancia promedio de la que habría de acuerdo con la composición orgánica de capital y a la tasa de plusvalía vigentes. En el caso de que los productos elaborados en condiciones rentistas se exportaran íntegramente la superganancia provendría de plusvalía transferida desde otros países. En tal caso se ocasionaría una elevación de la rentabilidad promedio de la economía beneficiada y un descenso correspondiente de la rentabilidad en los países importadores" (Valle, 1990, p. 152).

11 La tasa del ISIM, cuando fue creado, era de $3 \%$, porcentaje que correspondía 1.8 puntos porcentuales al Gobierno federal y el resto a los estados y municipios; aún cuando hasta 1970 sólo la mitad de las entidades federativas estaba coordinada. En 1973, luego de que la tasa del ISIM fue aumentada a 4\% las entidades federativas que aún no estaban coordinadas se gación, junto con otros gravámenes, al instituirse el Impuesto al Valor Agregado (IVA); en contrapartida, los estados y municipios incrementaron sus ingresos mediante la forma de transferencias no condicionadas o participaciones federales. Los municipios, adicionalmente, consiguieron como arbitrios propios los gravámenes sobre la propiedad inmobiliaria con la reforma de 1983 al artículo 115 de la Constitución. El avance que significó la reforma fiscal de 1983 tan sólo consistió en aumentar los ingresos autónomos de los municipios, pero solo tomando como base sus exiguos ingresos y no una modificación radical de la estructura impositiva centralista entre los integrantes del pacto federal, y ello básicamente en los municipios con un nivel suficiente de riqueza inmobiliaria.

En resumen, podemos decir que, considerando las condiciones particulares de México como país federal y la situación de crisis económica con sus efectos sobre las finanzas públicas, el Estado mexicano se vio en la necesidad de modificar su política económica en general, y fiscal en particular. Así, con el fin de revitalizar el sistema económico, social y político, el Gobierno federal modificó en 1980 el sistema de relaciones fiscales intergubernamentales a través del Sistema Nacional de Coordinación Fiscal $(\mathrm{SNCF})^{12}$ y, posteriormente, instituyó en el programa de gobierno 1982-1988 el lema de Fortalecimiento Municipal y Descentralización de la Vida Nacional ${ }^{13}$, y como elemento nodal de este programa se reformó

vieron obligadas a coordinarse. Este fue un paso sustancial en la construcción de un sistema impositivo coordinado (Jannetti, 1989, p. 770) y, por supuesto, centralizado.

12 Fiscalmente, el SNCF, consistió esencialmente en abrogar 18 impuestos, muchos de ellos locales, que gravaban distintas actividades productivas y comerciales, crear el Impuesto al Valor Agregado (IVA) y compensar a los gobiernos locales por la cesión de soberanías fiscales mediante transferencias no condicionadas, a partir de la conformación de una bolsa de recursos denominada Recaudación Federal Participable que incluye a los impuestos federales de base amplia como el Impuesto sobre la Renta, el Impuesto al Valor Agregado y el Impuesto Especial sobre Producción y Servicios entre otras fuentes de recaudación federal.

13 "Las políticas de descentralización y fortalecimiento de los gobiernos locales (...) son contemporáneas y están hermanadas con la crisis de los propios aparatos estatales, del modelo de acumulación, de los flujos de redistribución del Estado 'benefactor', de las formas de organización y uso del territorio y de los mecanismos de participación, representación y negociación política" (Massolo, 1989, p.121). 
el artículo 115 de la Constitución para, entre otros elementos, ceder a los ayuntamientos los impuestos a la propiedad inmobiliaria. Las acciones emprendidas bajo esta bandera fueron vistas en su momento como enormemente relevantes para lograr una sociedad más participativa y democrática. Se mostraba al efecto, por ejemplo, el enorme crecimiento en los ingresos autónomos municipales a partir de 1984, año en que se transfirieron los gravámenes a la propiedad inmobiliaria a los municipios.

Gráfica 3. México: Ingresos por ámbito de gobierno, antes de participaciones, $1970-1990$

(Miles de millones de pesos de 1980)

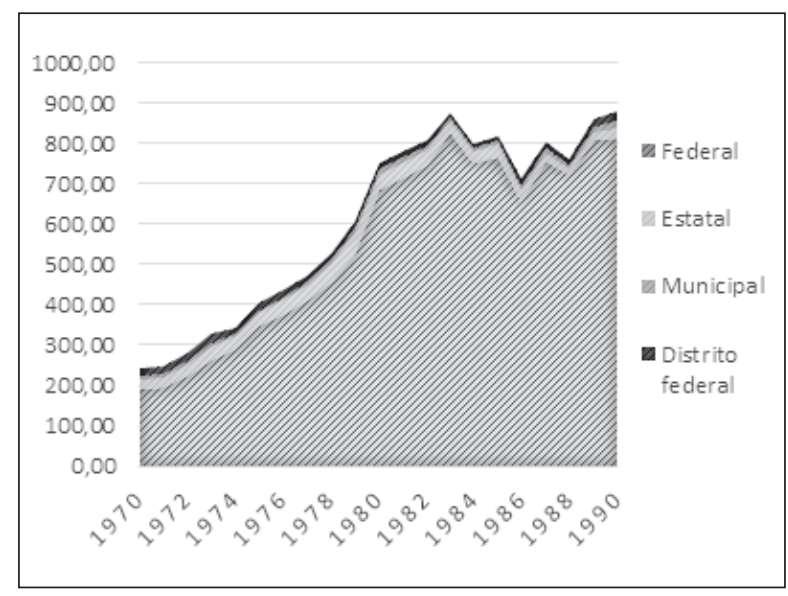

Fuente: Elaboración propia con base en INEGI (1982, 1984, 1990, 1991, 1992 y 1993).

Para comprender las implicaciones de la dinámica de la centralización fiscal en México se recurrió a una descomposición del proceso recaudatorio, siguiendo a Gerloff y Newmark (citados en Astudillo, 1989, p. 49-50) de modo tal que se han distinguido tres soberanías: i) la de objeto; ii) la de las sumas recaudadas y; iii) la administrativa. Con estos conceptos se concluye que el proceso de centralización fiscal se ha sustentado en el control por parte del Gobierno federal de los momentos más importantes, los que tienen que ver con las soberanías de objeto y administrativa, a través de las cuales puede definir, regular y vigilar el sistema fiscal en su conjunto, además de controlar el proceso de captación de la mayor parte de los recursos gubernamentales.
Al efecto considérese la Gráfica 3, que muestra los ingresos gubernamentales antes de la distribución de las transferencias no condicionadas y, por lo tanto, ilustra que la capacidad para decidir los montos, las formas y los tiempos en que el sector gubernamental obtiene sus ingresos se concentró en manos del Gobierno federal; en 1990 ese poder de decisión reunido en el Gobierno central alcanzó 92,6\% del total de los ingresos gubernamentales.

Gráfica 4. México: Ingresos por ámbito de gobierno, después de participaciones, 1970 - 1990

(Miles de millones de pesos de 1980)

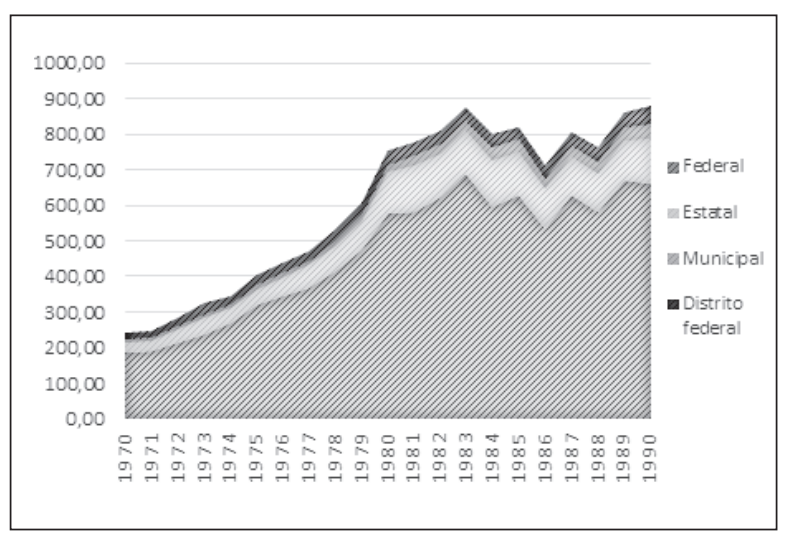

Fuente: Elaboración propia con base en INEGI (1982, 1984, 1990, 1991, 1992 y 1993).

En la Gráfica 4 se puede observar la evolución de los ingresos gubernamentales para cada ámbito gubernamental, después de que el gobierno federal distribuyó a entidades federativas y municipios los ingresos por participaciones federales; así, la Gráfica 4 muestra la soberanía de cada ámbito de gobierno sobre las sumas recaudadas e indica la capacidad de gasto que tiene cada uno de ellos. Destaca el efecto favorable en la redistribución del ingreso fiscal que tuvo la creación del Sistema Nacional de Coordinación Fiscal a partir de 1980, y que, sin embargo, se vio opacado por el estancamiento y la inestabilidad en la recaudación total que estando casi en su absoluta mayoría en poder del Gobierno federal, no logró evitar las consecuencias de la crisis y la década perdida en los años ochenta. 
La recaudación del Gobierno federal aumentó no sólo a partir de una absorción de responsabilidades fiscales a costa del resto de los ámbitos de gobierno sino que, teniendo como base aquélla y desarrollando una relativamente mayor racionalización y tecnificación de las prácticas fiscales, incrementó en términos reales tanto sus propios ingresos como los de los gobiernos municipales y estatales vía participaciones federales. Este crecimiento de los ingresos públicos, junto con la homogeneización del sistema fiscal, fueron los hechos más positivos del proceso de coordinación fiscal. Sin embargo, es pertinente señalar que el país aún muestra rezagos en los niveles de carga fiscal y, por lo tanto, en la capacidad de financiamiento del desarrollo del país, considerando no únicamente a los países de la Organización y Cooperación y Desarrollo Económico (OCDE), sino incluso de similar nivel de desempeño económico, como Chile, Argentina o Brasil. Lo anterior también se expresa en la estructura fiscal federal de México particularmente en los fiscalmente aún raquíticos ayuntamientos, en términos de su incapacidad para solventar las necesidades de servicios públicos de sus habitantes, ya no digamos para tener la capacidad para influir en las tendencias de su desarrollo. Esta situación era y es aún más grave en los municipios que carecen de factores endógenos de crecimiento, pues tienen escasas posibilidades de aumentar sus ingresos y, consecuentemente, de lograr mayores niveles de bienestar para su población (Tamayo \& Hernández, 2006).

Lograr un mayor equilibrio entre municipios-estados-Gobierno federal, en aras de avanzar hacia un desarrollo más equilibrado, democrático y participativo, no debe descansar por supuesto sólo en una proporcional fortaleza fiscal entre los tres niveles de gobierno, pero tampoco se puede lograr aquella tarea si no se dan pasos firmes en esta última. Es decir, la autonomía financiera de estados y municipios es indispensable, aún cuando no suficiente, para lograr un México más equilibrado.

\section{Conclusiones}

La teoría del federalismo fiscal si bien se ha renovado incorporando agentes y procesos políticos, considerado una mayor complejidad en la toma de decisio- nes de los agentes mediante el uso de los costos de transacción y otros aportes neoinstitucionales no ha roto con los postulados duros de una teoría ahistórica y atomista que le caracteriza. Por lo tanto, es necesario profundizar en marcos teóricos e interpretativos que analicen cómo las transformaciones contemporáneas sustentadas en las tecnologías de la comunicación, la informática, microelectrónica y la gestión flexible de la producción, en el contexto de una globalización que constituye el marco socioespacial del capitalismo contemporáneo, está determinando modificaciones en el sistema socioinstitucional en general y en las relaciones fiscales intergubernamentales, en particular. Cruciales en este sentido para incorporar al análisis y la formulación de propuestas teóricas y marcos interpretativos, y sólo a modo de ejemplo, son: profundizar en el análisis de las particularidades que asume el centralismo fiscal durante el cambio de paradigmas tecnoeconómicos y socioinstitucionales; el papel del Estado-nación en el entramado institucional que ha surgido de la conformación del capitalismo informático global; las consecuencias de la modificación de las bases de valorización y acumulación del capital en las posibilidades y limitaciones de lograr un excedente fiscal congruente con el nuevo entramado institucional $y$, por lo tanto, que garantice la estabilidad, el crecimiento y una menor desigualdad económica, social y espacial; la distribución y uso del excedente fiscal entre los distintos ámbitos de gobierno debe inscribirse en un análisis de las políticas derivadas del Consenso de Washington.

Avanzar en esta construcción teórica y metodológica constituye una tarea inaplazable, en la medida que, por ejemplo, una descentralización si bien puede considerarse una condición necesaria para conformar los equilibrios necesarios en el nuevo entramado institucional surgido del proceso de globalización, sino se aborda en el conjunto de relaciones tecnológicas, económicas, sociales y espaciales no se crearán las sinergias sistémicas necesarias para alcanzar un sistema social y económico que garantice bienestar económico, así como participación, democracia y justicia para todos.

Las reformas fiscales más importantes del periodo de estudio son las de 1973, 1980 y 1983. Las dos primeras constituyen momentos en los cuales el 
Gobierno federal aumenta su control sobre el proceso fiscal a costa sobre todo de las haciendas estatales; en 1973, logra que las entidades federativas económicamente más importantes se coordinen en materia de Impuesto sobre Ingresos Mercantiles, un gravamen federal y, en 1980, se crea el Sistema Nacional de Coordinación Fiscal. Muy por el contrario, la reforma de 1983 fortalece la soberanía financiera de los ayuntamientos, pero a costa de las finanzas estatales, al cederles la soberanía sobre el Impuesto Predial y el Impuesto sobre Traslación de Dominio. Un rasgo característico de todo el periodo es el incremento de las participaciones federales a los estados y municipios, sobre todo a estos últimos.

Los gobiernos de los estados son el ámbito de gobierno que se ha quedado con los tipos de ingreso menos redituables y eficientes, sumamente inelásticos a los procesos inflacionarios y recesivos, además de ser los menos beneficiados con los recursos fiscales que distribuye el Gobierno federal, lo cual ha ocasionado que registren un mayor deterioro relativo en sus ingresos.

Los efectos del proceso de centralización en el conjunto de las relaciones fiscales intergubernamentales, en el periodo que se analiza, han sido las de:

- Homogeneizar el sistema fiscal del país, evitando la concurrencia impositiva por los gobiernos federal, estatal y municipal;

- Un aumento importante de la recaudación pública total, aunque insuficiente para atender las necesidades del desarrollo del país;

- Una redistribución de los recursos fiscales que favoreció a los estados y municipios, de manera particular a estos últimos, pero que no ha significado una modificación sustancial del centralismo fiscal, particularmente si se considera el poder de decisión sobre el diseño y control del sistema recaudatorio que ha asumido el Gobierno federal, aun considerando la reforma de 1983;

- Congruencia entre la centralización estructural y fiscal, de modo tal que el Gobierno Federal concentra en sus manos una parte importante del ingreso nacional con fines de acumulación y regulación.

Entonces, podemos concluir que en las décadas que van de 1970 a 1990 se sentaron las bases institucionales del moderno centralismo fiscal y a ello contribuyó sustancialmente el Sistema Nacional de Coordinación Fiscal y a pesar de la reforma al artículo 115 Constitucional. Este centralismo fiscal se sustenta sobre todo, por un lado, en la conformación de un Gobierno central que detenta la soberanía de objeto y administrativa y, por lo tanto, la capacidad de decisión sobre el sistema tributario del país y, por otra parte, en unos gobiernos locales dependientes de la política de ingresos del Gobierno federal y de los recursos financieros que éste les proporciona.

El corolario de la consolidación del centralismo fiscal en México en las últimas décadas del Siglo XX, el cual se desenvolvió en el marco de un sistema político de partido único que duró más de seis décadas en el gobierno, son una debilidad extrema del sistema fiscal en su conjunto y no sólo de los gobiernos locales, sino además una clase política cada vez más alejada de los intereses de las mayorías, una debilidad institucional que ha impedido avanzar en una senda de crecimiento y equidad y que, por lo tanto ha sido presa de crecientes niveles de corrupción y criminalidad.

\section{Referencias}

Anguiano, R. (sf). Las finanzas del sector público en México. México, D. F: Universidad Nacional Autónoma de México.

Astudillo, M. (1989). México: la distribución de los ingresos públicos entre la federación y los estados. México, D. F.: Instituto de Investigaciones Económicas - Universidad Nacional Autónoma de México.

Case, K. E. \& Fair, R. (1993). Fundamentos de economía. México, D. F.: Prentice Hall.

Due, J. \& Friedlaender A. (1981). Análisis económico de los impuestos y del sector público. Buenos Aires: El Ateneo.

González, P. (1989). La democracia en México. México, D. F.: Ediciones Era.

Hodgson, G. (2001). El enfoque de la economía institucional. En: Revista Análisis Económico, Universidad Autónoma Metropolitana, XVI (33): 3-41.

Instituto Nacional de Estadística y Geografía INEGI (1982). Información sobre los ingresos gubernamentales 1970-1980. México, D. F.: INEGI.

Instituto Nacional de Estadística y Geografía INEGI (1984). Finanzas públicas estatales y municipales 1970-1982. México, D. F.: INEGI. 
Instituto Nacional de Estadística y Geografía INEGI (1990). E ingreso y el gasto público en México. México, D. F.: INEGI

Instituto Nacional de Estadística y Geografía INEGI (1991). Finanzas públicas estatales y municipales 1979-1988. México, D. F: INEGI.

Instituto Nacional de Estadística y Geografía INEGI (1992). E ingreso y el gasto público en México. México, D. F.: INEGI.

Instituto Nacional de Estadística y Geografía INEGI (1993). El ingreso y el gasto público en México. México, D. F.: INEGI

Instituto Nacional de Estadística y Geografía INEGI (2010). El ingreso y el gasto público en México 2010. México, D. F.: INEGI.

Jannetti, M. E. (1989). "La coordinación fiscal y los ingresos estatales". En Comercio exterior, 39 (9). Banco Nacional de Comercio Exterior S. N. C. México, D.F.: 769-774.

López, V. (2012). "El largo ciclo de endeudamiento". Límites y potencialidades de la economía de México al final del siglo XX. Disponible en: < http://www.mty.itesm.mx/dhcs/deptos/ri/ articulos/ecomex.html>

Massolo, A. (1989). "La descentralización de la gestión pública en México: la reforma municipal de 1983”. En Garza, G. (Comp.). Una década de planeación urbano-regional en México 1978 1988. México, D. F., El Colegio de México.

Moreno, J. G. (2005). "El postkeynesianismo y el evolucionismo: elementos de análisis del Estado ante la globalización". En Quivera, Universidad Autónoma del Estado de México, 7, (1): 172-196.
Moreno, J. G. (2007a). "El federalismo fiscal y el nuevo paradigma tecnoeconómico". En: Actas Latinoamericanas de Varsovia, Universidad de Varsovia, 30: 61-78.

Moreno, J. G. (2007b). "Los ingresos intergubernamentales en México 1980-2002: Una interpretación institucional evolucionista". En Quivera, Universidad Autónoma del Estado de México, 9, (2): 171-194.

Nacional Financiera NAFINSA (1988). La economía mexicana en cifras 1988. México, D. F.: NAFINSA.

Oates, W. E. (2005). "Toward a Second-Generation Theory of Fiscal Federalism". En: International Tax and Public Finance, Sprienger Science + Business Media Inc. (12): 349-373.

Stiglitz, J. E. (1988). La economía del sector público. Barcelona, Antoni Bosch, editor.

Tamayo, R. \& Hernández, F. (2006), "Financiamiento de la infraestructura local en México: Temas actuales y perspectivas", México, USAID-Tecnológico de Monterrey-USEmbassy. Disponible en: http:/www.indetec.gob.mx/informacion/articulos/Fpublicas/ Local_Infraestructure_Financing_SP.pdf.

Valle, A. (1990). "Renta petrolera y competencia capitalista". En: Economía. Teoría y práctica, Nueva época, (1):147-160.

Villareal, R. (1986). La contrarrevolución monetarista. México, D. F.: Fondo de Cultura Económica. 